\title{
PREPARATION AND CHARACTERIZATION OF NEUTRON DOSIMETER MATERIALS *
}

by

E. H. Kobisk and H. L. Adair

Introduction

There is a need for both stable and radioactive materials which can be placed in reactors and activated by neutrons to determine the neutron energy, spectra, flux, and fluence at a particular location. In addition, deposits of various radioactive materials are needed for use in precision neutron cross-section measurements. The materlals used for neutron monitors or for precision cross-section measurements must be accurately defined and contain minimum amounts of impurities. The Isotopes

Division at the Oak Ridge National Laboratory has established a program for providing neutron dosimeters as well as materials used for precision neutron cross-section measurements.

\section{Preparation of Dosimeters}

In addition to being well defined and containing minimum amounts of impurities, the encapsulated dosimeter materials should meet the following criteria. ${ }^{1}$

1. The materials should have peak activation characteristics at different neutron energies.

*Research sponsored by the U. S. Atomic Energy Commission under contract with the Union Carbide Corporation, 
Table 1. Vanadium Metal Used for Dosimeter Capsules

$$
\mathrm{V}-99.995 \%
$$

Spark Source Mass Analysis

ppm

Al

0.05

B

$<0.02$

$\mathrm{Ca}$

0.8

Co

$<1.0$

$\mathrm{Cr}$

$<10.0$

Cu

0.5

$\mathrm{Fe}$

$<3.0$

Hf

3.0

$\mathrm{K}$

2. 0

Mg

0.1

Mn

$<3.0$

Na

$<0.5$

N1

$<3.0$

P

0.2

Si

3. 0

Ta

10. 0

$\mathrm{Zr}$

1. 0 


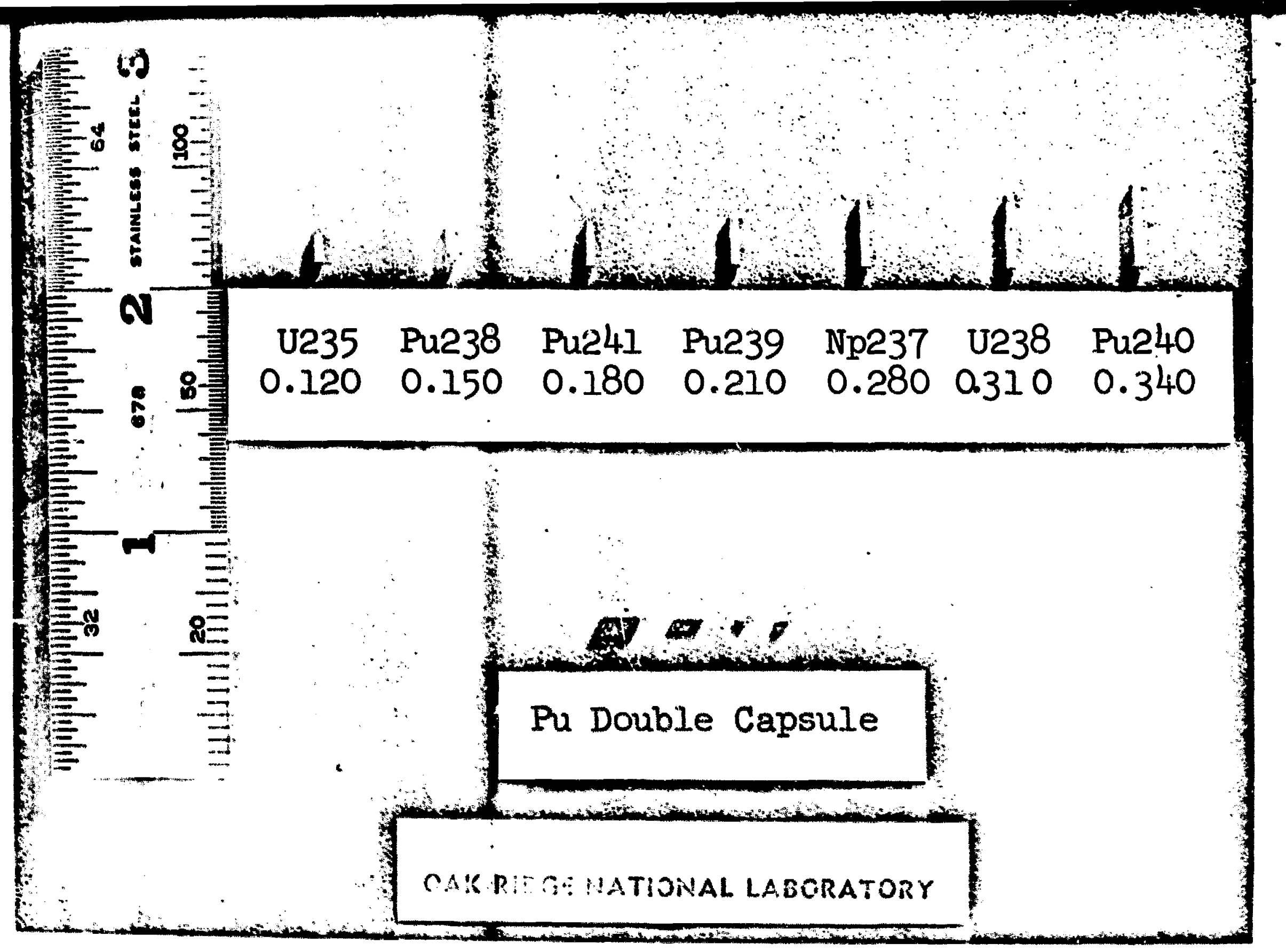


2. The dosimeter and encapsulating materials should have hlgh melting polnts, normally $>1000^{\circ} \mathrm{F}$.

3. The dosimeter materials should produce product radioIsotopes whose half lives and radiation characteristics are accurately known and are amenable to direct counting through the cepsule without dissolution.

The dosfmeters prepared by the Isotopes Division at the Oak Ridge National Laboratory are encapsulated in hfgh purity vanadium (99.995\%) which contains $\leq 10$ ppm tantalum. The low tantalum content is necessary because tantalum has a high cross section for fast neutrons and the activation products produced interfere with the arsiysis of the activation produsts produced in the dosimeter material. A typical spark-source moss spectrographic analysts of the vanadium is shown in Table 1. Thus far, dosimeters of ${ }^{6 \mathrm{LI}},{ }^{10} \mathrm{~B},{ }^{45} \mathrm{Sc},{ }^{232} \mathrm{Th},{ }^{235} \mathrm{U},{ }^{230} \mathrm{U},{ }^{237} \mathrm{~Np},{ }^{234} \mathrm{Pu},{ }^{239} \mathrm{Pu}$, and M"Pu have been prepared. Normally, the elemental form is used for the stable materials and the radioactive materials are in oxide form.

: : The vanadium.capsules uged to encapsulate the doslmeter materials are shown in Fig. 1. The capsules have a $1.27-\mathrm{mm}$ diam and yary in length from $3.05 \mathrm{~mm}$ to $8.64 \mathrm{~mm}$. The internal cavity $1 \mathrm{~s} 0.76-\mathrm{mm}$ diam and varies in depth from $2.28-\mathrm{mm}$ to $7.87-\mathrm{mm}$. The amount of material loaded into each capsule varies from $\sim 1-10 \mathrm{mg}$, depending upon the particular isotope. The material type is identified by the length of the capsule and each Indivtdual capsule is identified by a dot coding system. ${ }^{2}$ 
The procedure for loading the capsules is described in Ref. 2 and will not be described here.

After the dosimeter materials have been encapsulated in a welded vanadium capsile and decontaminated, if they contain radioactive materials, the capsules are leak checked by using an ethylene glycol vacuum leak test procedure which will detect leaks as small 83 $10^{-4} \mathrm{~cm}^{3} / \mathrm{min}$. In addition, the dosimeters are heated to $800^{\circ} \mathrm{C}$ in argon for one hour and leak checked again. At this stage the stable materials are ready for shipment. However, the radioactive materlals are given a one-wsek shelf test after which they are checked for contamination. At this stage, if the dosimeters contain any removable detectable contamination, they are rejected for shipment.

\section{Characterization of Dosimeters.}

The ampunt of materfal contained in each dosimeter is determined initially by welght difference ising a Mettler MS micröbalance. The accuracy of the weight of material in each monitor containing $>1 \mathrm{mg}$ of material is A $\therefore \because{ }^{239} \mathrm{PuO}_{2}$, and ${ }^{237} \mathrm{NpO}_{2}$, gamma counting, using $\mathrm{a} 7.6 \mathrm{~cm}$ by $7.6 \mathrm{~cm}$ NaI(T) detector, is presently being used to verify the amount of encapsulated material after the capsules have been welded and decontaminated. Figures 2 through 5 șhow. typlcal gamma-ray spectra oḅtained for ${ }^{235} \mathrm{U},{ }^{23} \mathrm{U},{ }^{239} \mathrm{Pu}$. and ${ }^{237} \mathrm{~Np}$ dosimeters. For the ${ }^{235} \mathrm{U}$ dosimeters, the number of gamma 


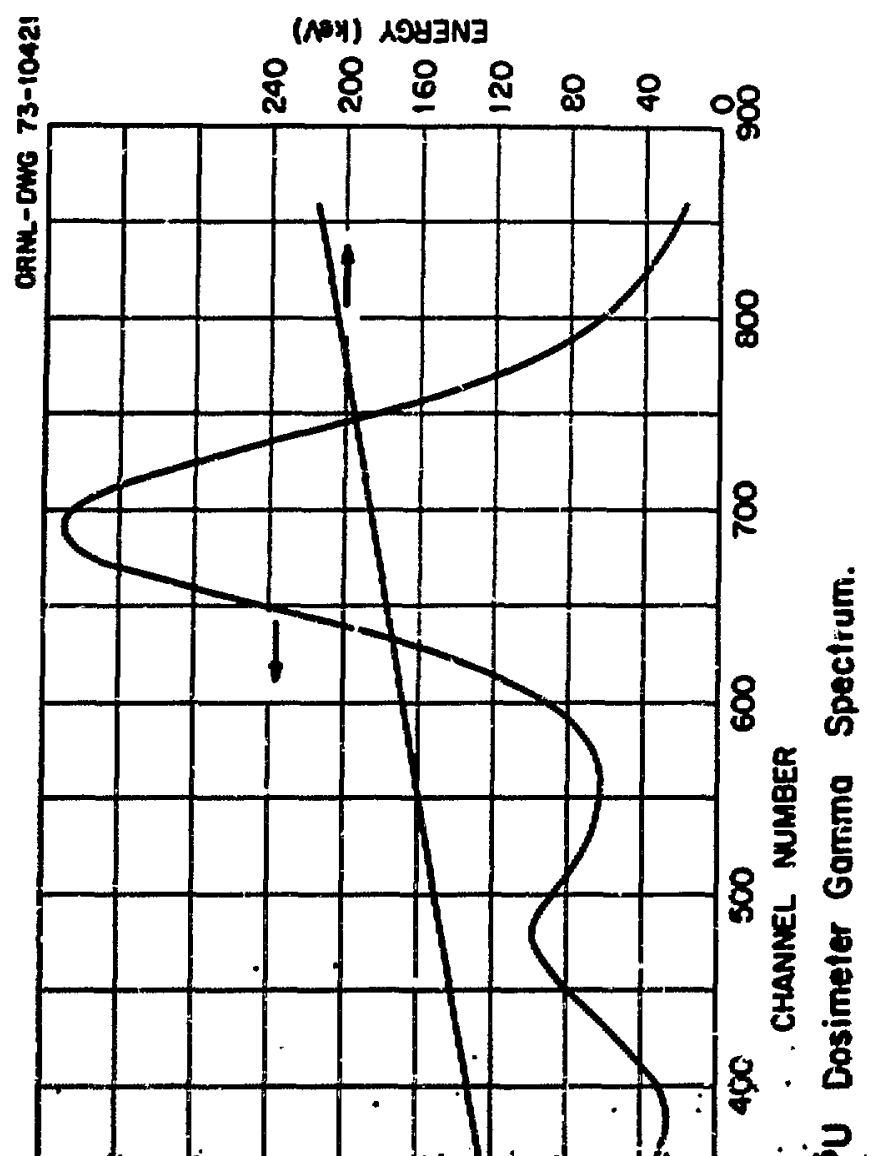

$\therefore \quad a_{0}$

F

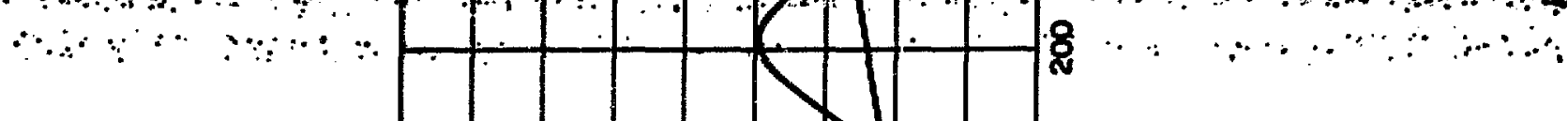

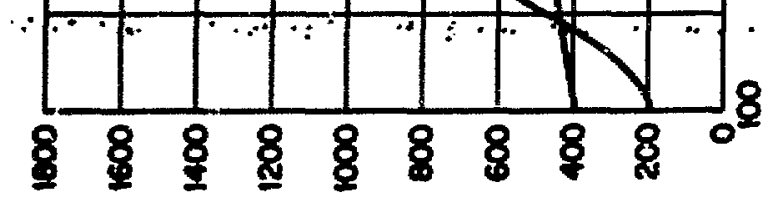




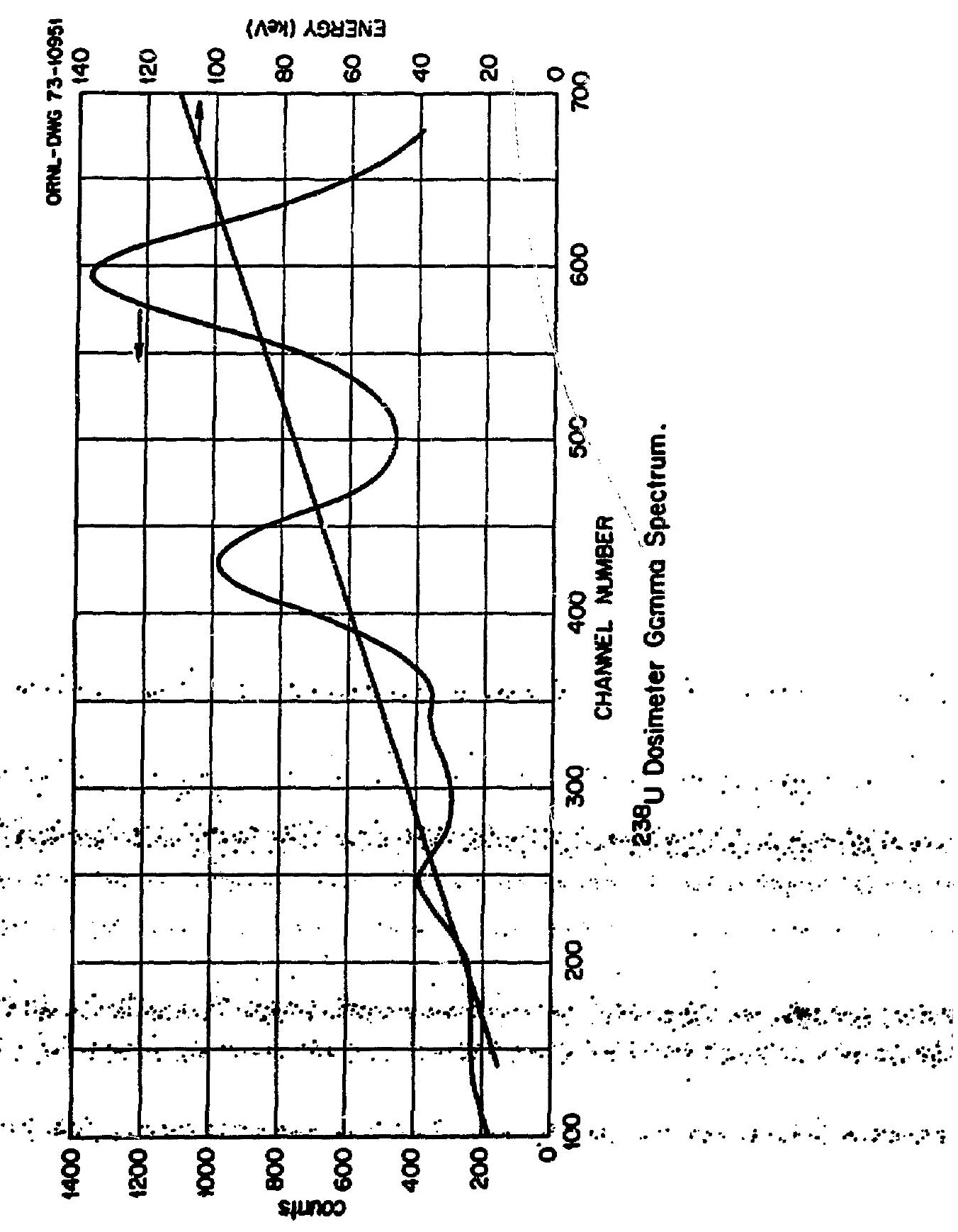

ง 


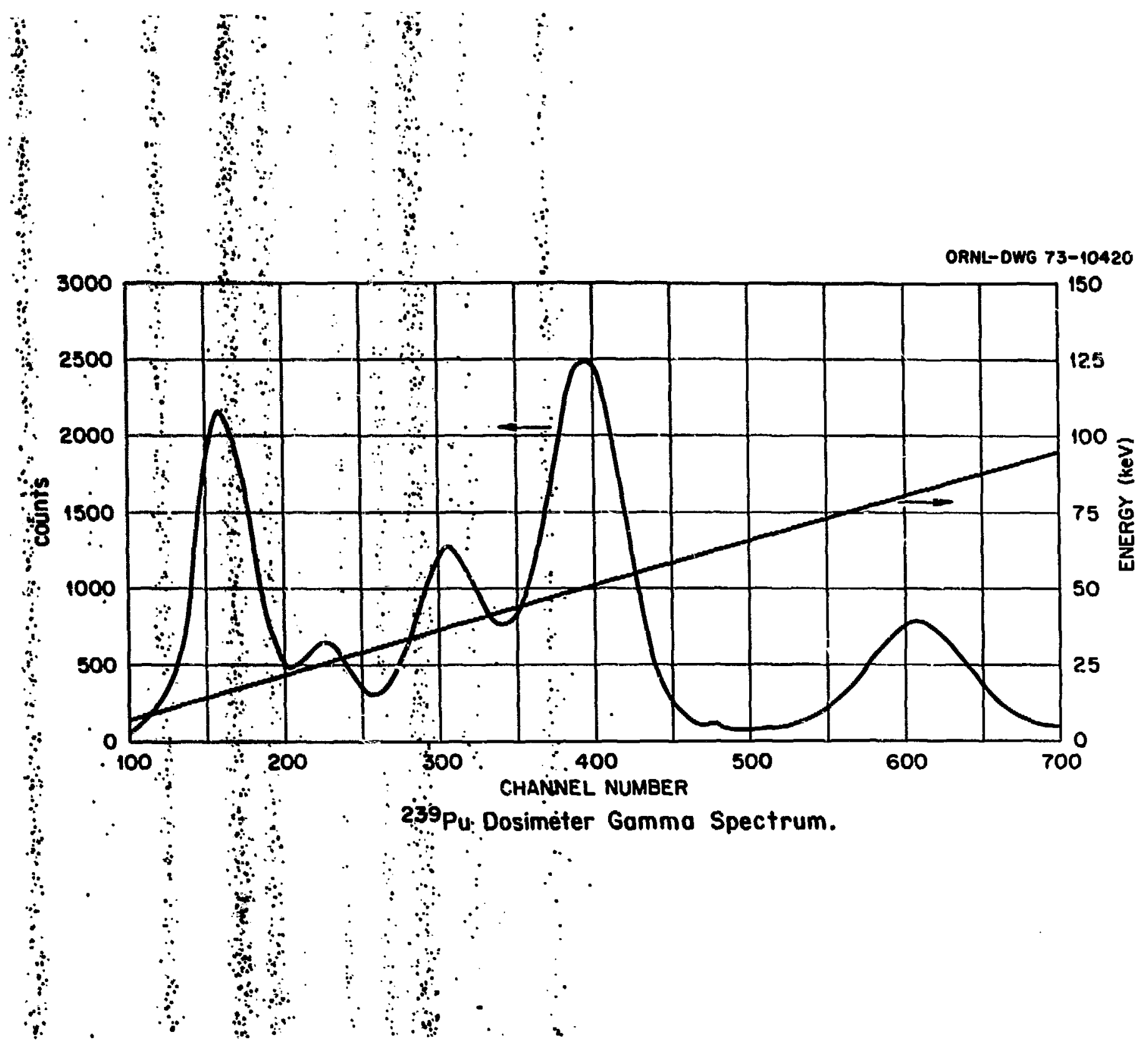


One of the reasons for gamma counting the dosimeters was to determine If materlal was being lost during the welding process because on some of the smalici capsules, for example ${ }^{235} \mathrm{U}$, the material, when loaded, is very close to the weld zone. Table 2 shows the gamma counting results for ${ }^{235} \mathrm{U}$ dosimeters which were counted before and after welding. As can be seen from the table, no variations except those due possibiy to capsule thicknesses were noted. Also, the number of gamma counts per minute per microgram shows a variation among the dosimeters of $\sim 1.5 \%$. The counting time for each dosimeter was 10,000 sec. In Table 3 the results obtained for ${ }^{238} \mathrm{U}$ dosimeters before and after welding are shown. Again, no material was lost in the welding process and the variation in gamma counts per minute per microgram among the dostmeters is $1.7 \%$.

\section{Archive Samples}

$\therefore$ For further verification or reanalysis of the batches of isotopic materials used tn the dosstmeter program, archive samples of ${ }^{235} \mathrm{U},{ }^{238} \mathrm{U}$, ${ }^{237} \mathrm{~Np}$, and ${ }^{239} \mathrm{Pu}$ have been prepared and encapsulated for storage at the

Odk Ridge National Laboratory Each isotope foxtde and metal f wa's characterized by the following analysis.

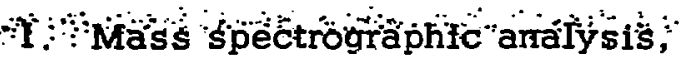
$.2 ;:$ Spark-source mass spectrographic analysis,

3. Amount of the major element per unit weight of material.

In addition, the moisture content of the oxide samples was determined.

The results of these analyses are shown in Tables 4 through 7 . 
Table 2

${ }^{235} \mathrm{U}$ Dosimeters $y$-Counted Before Welding

$\begin{array}{lcccccc}\begin{array}{c}\text { Dosimeter } \\ \text { No. }\end{array} & \begin{array}{c}\text { Oxide Wt. } \\ (\mathrm{mg})\end{array} & \begin{array}{c}\text { Elemental Wt. } \\ (\mathrm{mg})\end{array} & \begin{array}{c}\text { Gamma Counts } \\ \text { Minus } \\ \text { Background }\end{array} & & \begin{array}{c}\text { Couni Rate } \\ \text { per min. }\end{array} & \begin{array}{c}\text { Count Rate } \\ \text { per min. } \\ \text { per mg }\end{array} \\ \text { Std. }-1 & 2.671 & 2.259 & 291407 & 1748.40 \pm 2.23 & 773.97 \\ \text { Std. }-5 & 0.973 & 0.823 & & 108705 & 652.22 \pm 1.42 & 792.49 \\ \text { Std. }-7 & 3.406 & 2.881 & 370947 & 2225.64 \pm 2.50 & 772.52 \\ \text { Std. }-8 & 2.328 & 1.969 & & 259893 & 1559.33 \pm 2.11 & 791.94 \\ \text { Std. }-9 & 1.404 & 1.188 & 154198 & 925.17 \pm 1.66 & 778.76\end{array}$

${ }^{235} \mathrm{U}$ Dosimeters $\gamma$ Jounted After Welding

\begin{tabular}{|c|c|c|c|c|c|}
\hline Std. -1 & 2.671 & 2.259 & 288141 & $1728.81 \pm 2.22$ & 765.30 \\
\hline Std. -5 & 0.973 & 0.823 & 108827 & $652.95 \pm 1.42$ & 793.38 \\
\hline $\begin{array}{l}\operatorname{td}:-7 \\
\operatorname{td}:-8\end{array}$ & $\begin{array}{r}3: 406 \\
2.328\end{array}$ & 2:881 & $\begin{array}{l}369986 \\
260414\end{array}$ & $\begin{array}{l}2219.87 \pm 2.50 \\
1562.45 \pm 2.11\end{array}$ & $\begin{array}{r}770.52 \\
793.52\end{array}$ \\
\hline Std. -9 . & 1. 404 & 1.188 & 155151 & $930.89 \pm 1.66$ & 783.58 \\
\hline
\end{tabular}

bo 
Table 3

${ }^{238} \mathrm{U}$ Dosimeters $y$-Counted Before Welding

$\begin{array}{lcccccc}\begin{array}{c}\text { Dosimeter } \\ \text { No. }\end{array} & \begin{array}{c}\text { Oxide Wt. } \\ (\mathrm{mg})\end{array} & \begin{array}{c}\text { Elemental Wt. } \\ (\mathrm{mg})\end{array} & \begin{array}{c}\text { Gamma Counts } \\ \text { Minus } \\ \text { Background }\end{array} & \begin{array}{c}\text { Count Rate } \\ \text { per min. }\end{array} & \begin{array}{c}\text { Count Rate } \\ \text { per min. } \\ \text { per mg }\end{array} \\ \text { Std. }-1 & 8.265 & 6.987 & & 93062 & 186.12 \pm 0.52 & 26.64 \\ \text { Std. }-3 & 8.526 & 7.208 & & 96880 & 193.76 \pm 0.52 & 26.88 \\ \text { Std. }-4 & 8.660 & 7.321 & 98494 & 196.99 \pm 0.53 & 26.91\end{array}$

${ }^{238} \mathrm{U}$ Dosimeters $\gamma$-Counted After Welding

$\begin{array}{llllll}\text { Std. }-1 & 8.265 & 6.987 & 95171 & 190.34 \pm 0.52 & 27.24 \\ \text { Std. }-3 & 8.526 & 7.208 & 95622 & 191.24 \pm 0.52 & 26.53 \\ \text { Std. }-4 & 8.660 & 7.321 & 98488 & 196.98 \pm 0.53 & 26.91\end{array}$

Pand A 
Table 4. Analyses for the Major Element (The Amount of the Major Element Per Unit Weight of Material)

\begin{tabular}{lccc} 
Batch No. & $\begin{array}{c}U \\
(\mathrm{mg} / \mathrm{g})\end{array}$ & $\begin{array}{c}\mathrm{Np} \\
(\mathrm{mg} / \mathrm{g}) \\
\pm 0.5 \%\end{array}$ & $\begin{array}{c}\mathrm{Fu} \\
(\mathrm{mg} / \mathrm{g})\end{array}$ \\
\hline $\begin{array}{l} \pm 0.5 \% \\
\text { U-235-264-C }\end{array}$ & 846.8 & & \\
U-235-264-CM & 994.4 & & \\
U-238-ES-Z & 845.4 & & \\
U-238-ES-ZM & 994.8 & & 895.2 \\
Pu-239-453-B-O & & & 982.5 \\
Pu-239-453-B-M & & & \\
Np-237-NP-21 & & 861.0 & \\
Np-237-24HP & & 874.5 &
\end{tabular}

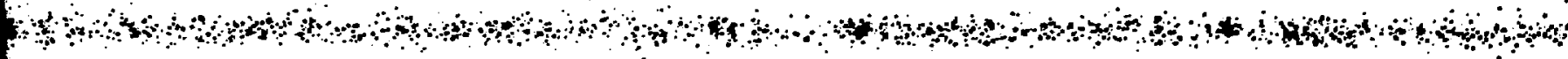
4 a 
Table 5. Isotople Composition of the Major Element

\section{Batch U-235-264-C}

\section{Isotope}

233

234

235

236

238

233

234

235

236

238

\section{3}

\section{Atom Percent}

$<0.0005$

$0.03+ \pm 0.001$

$99.89 \pm 0.01$

$0.025 \pm 0.001$

$0.052 \pm 0.002$

\section{Batch U-235-264-CM \\ Batch $U-235-264-C M$}

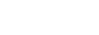

\section{Batch U-238-ES-Z}

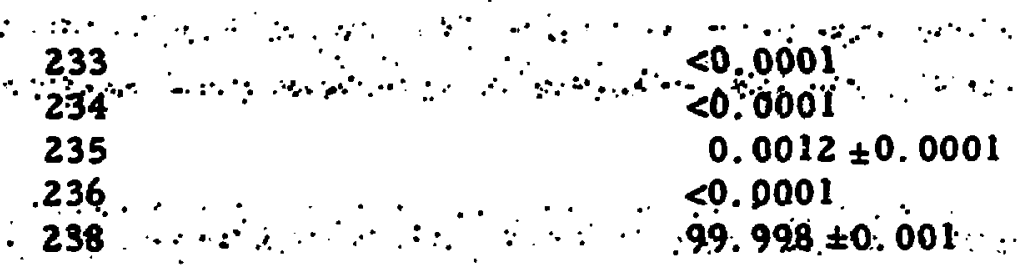

Batch U-Z3B-ES-ZM
233
234
$<0.0001$
$<0.0001$
235:
$0.0015 \pm 0.0001$
236 .
$<0.000 \mathrm{i}^{\circ}$

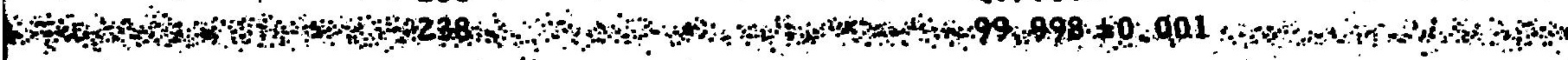
8

Batch Pu-23.9-453-B-M

$\begin{array}{llll}238 \\ 239 \\ 240\end{array} \cdots \cdots \cdots, \quad \begin{aligned} & 50.002 \\ & 99.11 \pm 0.01 \\ & 0.880 \pm 0.005\end{aligned}$

$241.0 .010 \pm 0.001$ 
Table 6. Impurity Analysis

(Wt. ppm)

\begin{tabular}{|c|c|c|c|c|c|c|}
\hline $\begin{array}{l}{ }^{235} \mathrm{U} \\
264-\mathrm{CM}\end{array}$ & $\begin{array}{r}{ }^{236} \mathrm{U} \\
\mathrm{ES}-2 \\
\end{array}$ & $\begin{array}{c}{ }^{23} U \\
E S-Z M \\
\end{array}$ & $\begin{array}{c}23{ }^{23} \mathrm{Pu} \\
453-\mathrm{B}-\mathrm{M} \\
\end{array}$ & $\begin{array}{c}{ }^{239} \mathrm{Pu} \\
453-\mathrm{B}-\mathrm{O} \\
\end{array}$ & $\begin{array}{l}{ }^{237} \mathrm{~Np} \\
\mathrm{NP21} \\
\end{array}$ & $\begin{array}{c}{ }^{237} \mathrm{~Np} \\
\text { NP24HP } \\
\end{array}$ \\
\hline 30 & 5 & 30 & 1,000 & 15 & 1 & 2 \\
\hline$<1$ & 1 & $<1$ & & 1 & 1 & $<1$ \\
\hline$<0.5$ & 2 & $<0.5$ & $0 . E$ & 0.2 & $<0.5$ & $<0.5$ \\
\hline$<1$ & $<1$ & $<1$ & $<1$ & $<1$ & $<1$ & $<1$ \\
\hline 2 & 15 & 2 & 40 & 8 & 8 & 2 \\
\hline$<1$ & $<1$ & $<1$ & $\leq 1$ & $<1$ & $<1$ & $<1$ \\
\hline 30 & 1 & 30 & 20 & $<1$ & $<1$ & $<1$ \\
\hline 10 & 2 & 10 & 40 & 6 & 4 & 2 \\
\hline 80 & 25 & 200 & 400 & 10 & 2 & 4 \\
\hline$<1$ & $<1$ & $<1$ & 20 & 10 & $\leq 1$ & 1 \\
\hline$<1$ & 2 & 1 & 100 & 1 & $<1$ & $<1$ \\
\hline$? \div$ & $<1$ & 7 & 7 & $<i$ & $<1$ & $<1$ \\
\hline$<1$. & 51 & $\leq 1$ & $\leq 1 \ldots$ & 1 & $<i$ & $\leq 1$ \\
\hline 100 & 2 & 30 & 30 & 1 & 1 & 1 \\
\hline$<1$ & $2.0 \ldots$ & $<1$ & $\therefore \quad \ldots \quad 1$ & $<1$. & $<1$ & $\leq \mathbf{1}$ \\
\hline$<1$ & $<1$ & & $\theta$ & $\leq 1$ & $<1$ & \\
\hline 20 & 3 & 20 & 20 & 10 & $<1$ & 3 \\
\hline & 5 & & & 1 & & 2 \\
\hline 1 & 10 & 1 & 10 & 1,000 & 4 & 4 \\
\hline 2 & $\because 10 \ldots$ & 2. & $\therefore \because \leqslant 1$ & $\therefore<1$ & $<1 \therefore$ & $\therefore \therefore<1 \quad$ \\
\hline
\end{tabular}

A

\begin{tabular}{l|l|l|l|l|l|l}
20 & 100 & 200 &.$<1$ & $<1$ & $<1$ & $<1$
\end{tabular}

\begin{tabular}{|c|c|c|c|c|c|c|}
\hline$<i$ & $<1$ & 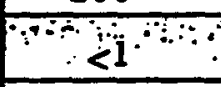 & $\cdots+\theta^{2}$ & $\because 0^{2} \div \div$ & 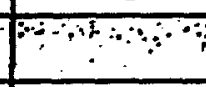 & 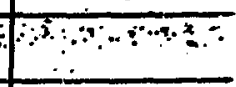 \\
\hline$\therefore 1$ & $<1$ & $<1$. & .10 & 2 & 2 & $<1$. \\
\hline$<1$ & $<1$ & 2 & 2 & $<1$ & & $<1$ \\
\hline
\end{tabular}

\begin{tabular}{|c|c|c|c|c|c|c|}
\hline$M^{\prime} \cdot \cdots$ & 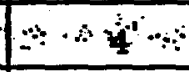 & $\therefore \because 640$ & a 10 & $\because-\because \div 1: \div \div \cdots$ & 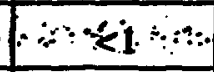 & 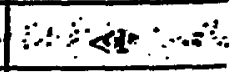 \\
\hline$<1$ & $<1$ & $<1$ & 1 & & $\mathbf{M}$ & $\mathbf{M}$ \\
\hline$<1$ & $\leq 10$ & 3 & $\mathbf{M}$ & $\mathbf{M}$ & 1 & $<1$ \\
\hline$<1$ & $<1$ & $<1$ & $<1$ & $<1$ & $<1$ & $<1$ \\
\hline
\end{tabular}




\section{Table 7. Moisture Content of Oxides}

(Numbers given are ppm $\neq 2.5 \%$ )

\section{Batch No.}

U-235-264-C

U-238-ES-2

Np-237-NP21

Np-237-NP24HP

Pu-239-453-B-O
Room

Temperature

\section{4}

698

$<10$

$<10$

1321

;

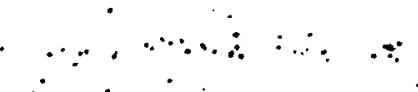




\section{Preparation of Well-Defined Layers for Reaction Rate and Neutron Gross-Section Measurements}

Thin filme of ${ }^{235} \mathrm{JO}_{2}$ and ${ }^{239} \mathrm{PuO}_{2}$ were deposited by vacuum evaporationcondensation ( $<10^{-6}$ torr) onto platinum and aluminum substrates for use In reaction rate and neutron cross-section determinations.

The material was deposited by the electron bombardment heating and vaporization of the oxide materials. A schematic of the $270^{\circ}, 10 \mathrm{~kW}$ evaporation source used is shown in Fig. 6. Two ${ }^{239} \mathrm{PuO}_{2}$ and two ${ }^{235} \mathrm{UO}_{2}$ targets were prepared for the National Bureau of Standards to be used for obtaining reaction rates in support of the Interlaboratory LMFBR Reaction Rate Program and for reactor dosimetzy in general. ${ }^{3}$ The mass analyses . of the ${ }^{235} \mathrm{U}$ and ${ }^{239} \mathrm{Pu}$ used are shown in Tables 8 and 9 " The materials were deposited on $1.27-\mathrm{cm}$ diam polished platinum substrates. The $\because \because \quad \because$ amount of material on each target wạs determined by alpha counting in a $\therefore$ low geometry counting system. The difference in count rates among the samples made it necessary to count the targets at different positions in the low geometry counter. The ${ }^{235} \mathrm{U}$ targets were positioned $1.27-\mathrm{cm}$ from the sllicon detector and the 239 purgets were posithoned at 15,24

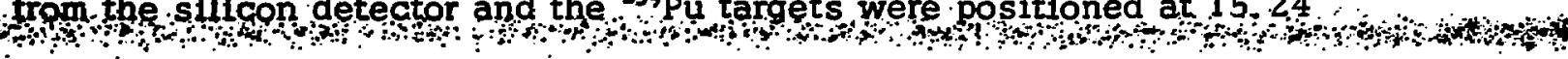
or 38. 10- $\mathrm{cm}$ depending on their thickness. The geometry factors for the ${ }^{239} \mathrm{Pu}$ analyses were determined by using a standard ${ }^{241} \mathrm{Am}$ source. The amount of ${ }^{235} \mathrm{U}$ contained on the targets was determined by destructively anălyzing similar targets and comparing count rates between thọse-prepared : for NBS and those destructively analyzed. The geometry factor obtained by using the count rate and the actual ${ }^{235} \mathrm{U}$ material determined for the 


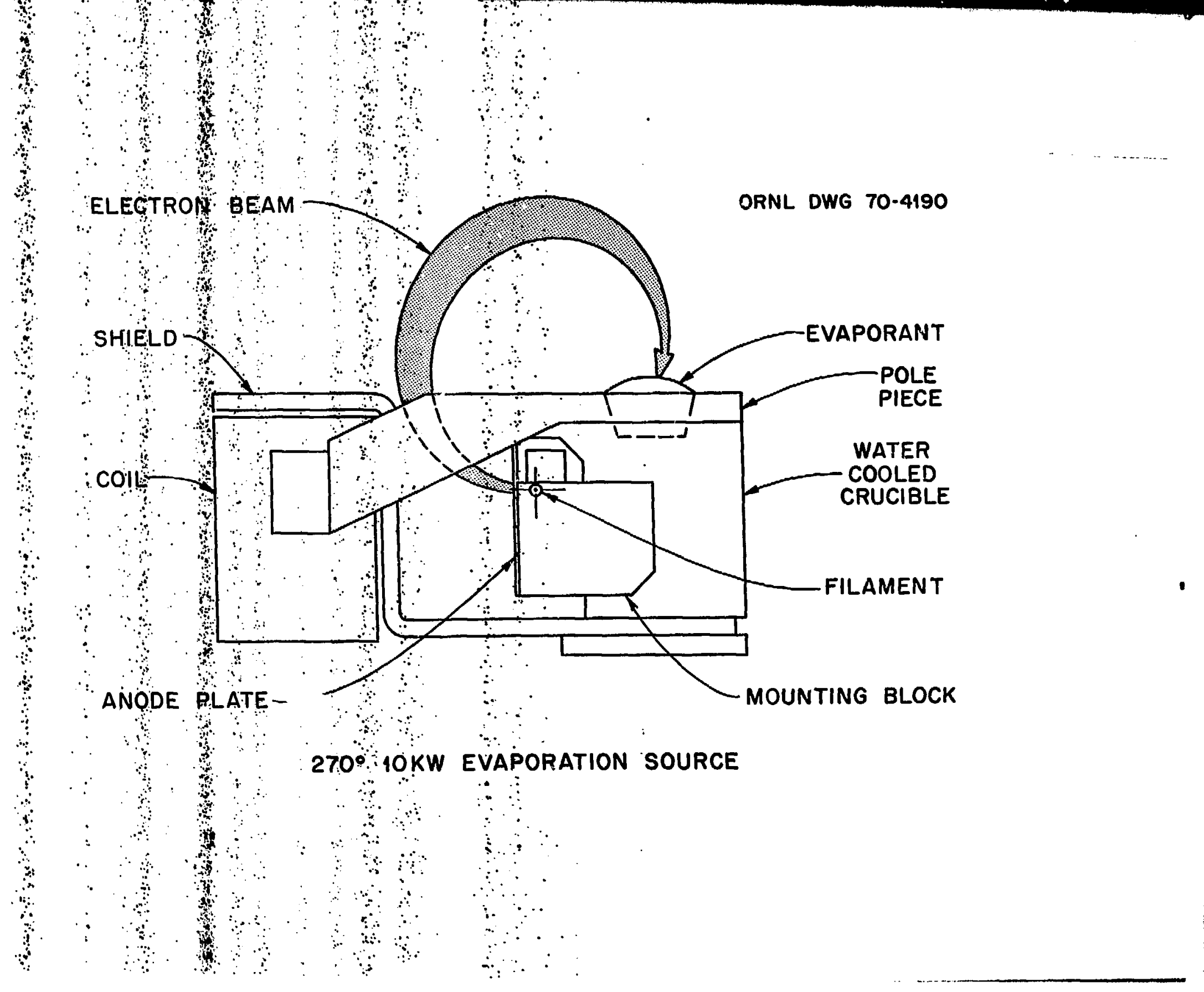




\section{Table 8. ${ }^{235} \mathrm{U}$, Batch $264 \mathrm{C}-1$}

\section{Isotope}

234

235

236

238

\section{Atom Percent}

$0.0345 \pm 0.0009$

$99.699 \pm 0.002$

$0.0252 \pm 0.0005$

$0.241 \pm 0.002$

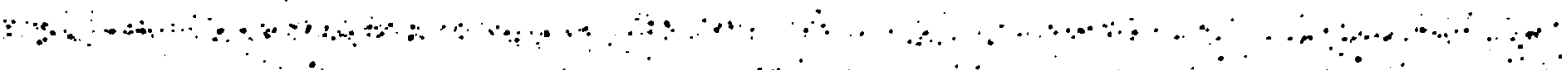

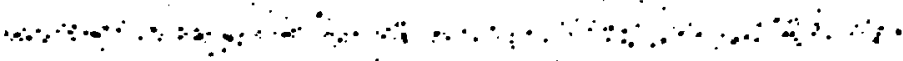

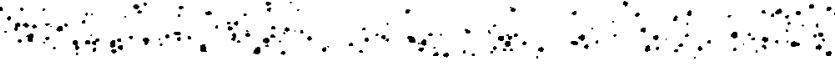
a For A

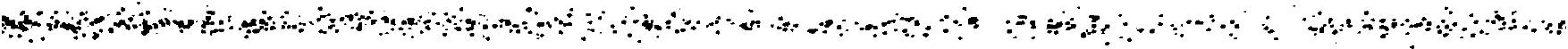


Table 9. ${ }^{239} \mathrm{Pu}$, Batch $277 \mathrm{~A}$

\section{Isotope}

238

239

240

241

242

244
Atom Percent

$\leq 0.0002$

$99.978 \pm 0.002$

$0.021 \pm 0.002$

$0.0005 \pm 0.0003$

$0.0005 \pm 0.0003$

$<0.0002$

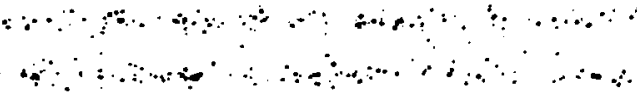

a

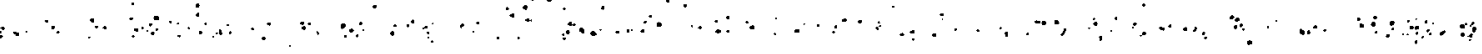

$\therefore=0,+\cdots$

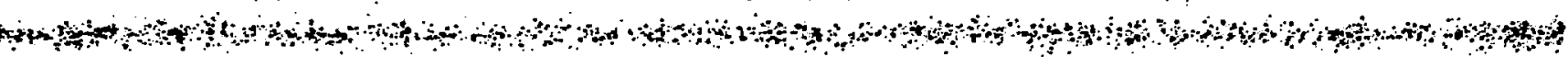
A A 
destructively analyzed ${ }^{235} \mathrm{U}$ targets was also used to calculate the amount of material contained on the NBS ${ }^{235} \mathrm{U}$ targets. As expected, the last two methods gave essentially the same results. The results for the ${ }^{235} \mathrm{U}$ and ${ }^{239} \mathrm{Pu}$ NBS targets is summarized in Table 10.

Similar procedures were used to prepare $15{ }^{235} \mathrm{UO}_{2}$ and $24{ }^{239} \mathrm{PuO}_{2}$ targets for use in fission chambers at ORNL to determine precision cross-section measurements. In each case the material was deposited by electron bombardment evaporation condensation onto a 5-cm diam spot centered on a $10-\mathrm{cm}$ diam by $0.001-\mathrm{cm}$ thick aluminum substrate. The substrates were located approximately $25 \mathrm{~cm}$ from the source material and were rotated to improve the unformity of the deposited material. ${ }^{4}$ Typical spectra for the ${ }^{235} \mathrm{U}$ and ${ }^{239}$ Pu.targets are shown in Fłgs: 7. and .8 . In the $\mathrm{U}$ spectrum the two ${ }^{234} \mathrm{U}$ peaks (4.773 and $4.722 \mathrm{MeV}$ ) are the làst two peaks shown in Fig. 7 . The remalnder of the peaks are due to ${ }^{235} \mathrm{U}$ and small contributions from ${ }^{236} \mathrm{U}$ and ${ }^{238} \mathrm{U} \cdot$ The energy calibration is $1.2 \mathrm{keV}$ per channel. The ${ }^{239} \mathrm{Pu}$ spectrum (Fig. 8) was obtained for $\mathrm{a}$ ${ }^{239} \mathrm{Pu}$ thickness of $60 \mathrm{gg} / \mathrm{cm}^{2}$ It shows the 5 105 and unresolved 5.143

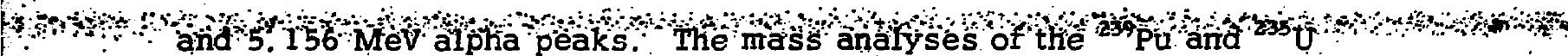
materals is shown in Tables 9 and 11 respectively:

Althọugh the ${ }^{235} \mathrm{U}$ targets were alpha counted to get approximate

weights, gamma counting was used for the final determination because of the counting time involved. Alpha counting was used to determine the ${ }^{239} \mathrm{Pu}$ thickness. In each case a target was destructively analyzed to 


\section{Table 10. Isotope Content of NBS Targets}

$\begin{array}{lc}\begin{array}{l}\text { Target } \\ \text { No. }\end{array} & \frac{{ }^{235} \mathrm{U}(\mu \mathrm{g})}{25 \mathrm{~K}-1-1} \\ 25 \mathrm{~K}-02-1 & 126.3 \pm 1.5 \% \\ & 28.5 \pm 2 \% \\ 49 \mathrm{~K}-01-2 & { }^{239} \mathrm{Pu}(\mu \mathrm{g}) \\ 49 \mathrm{~K}-4-1 & 13.3 \pm 1 \% \\ \end{array}$

- a ar on a d 


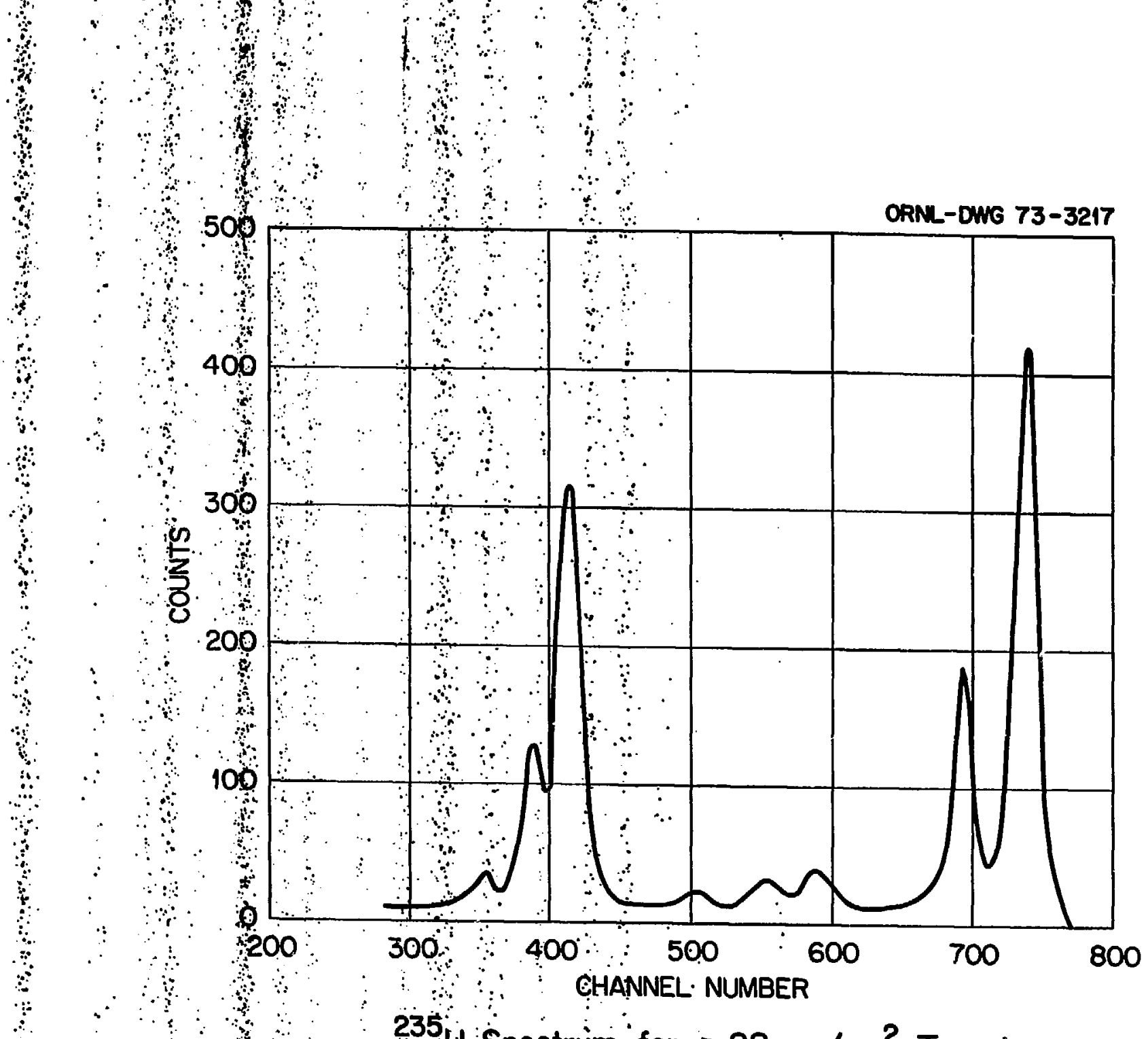

$235 \mathrm{U}$ Spectrum for a $28 \mu \mathrm{g} / \mathrm{cm}^{2}$ Target. 


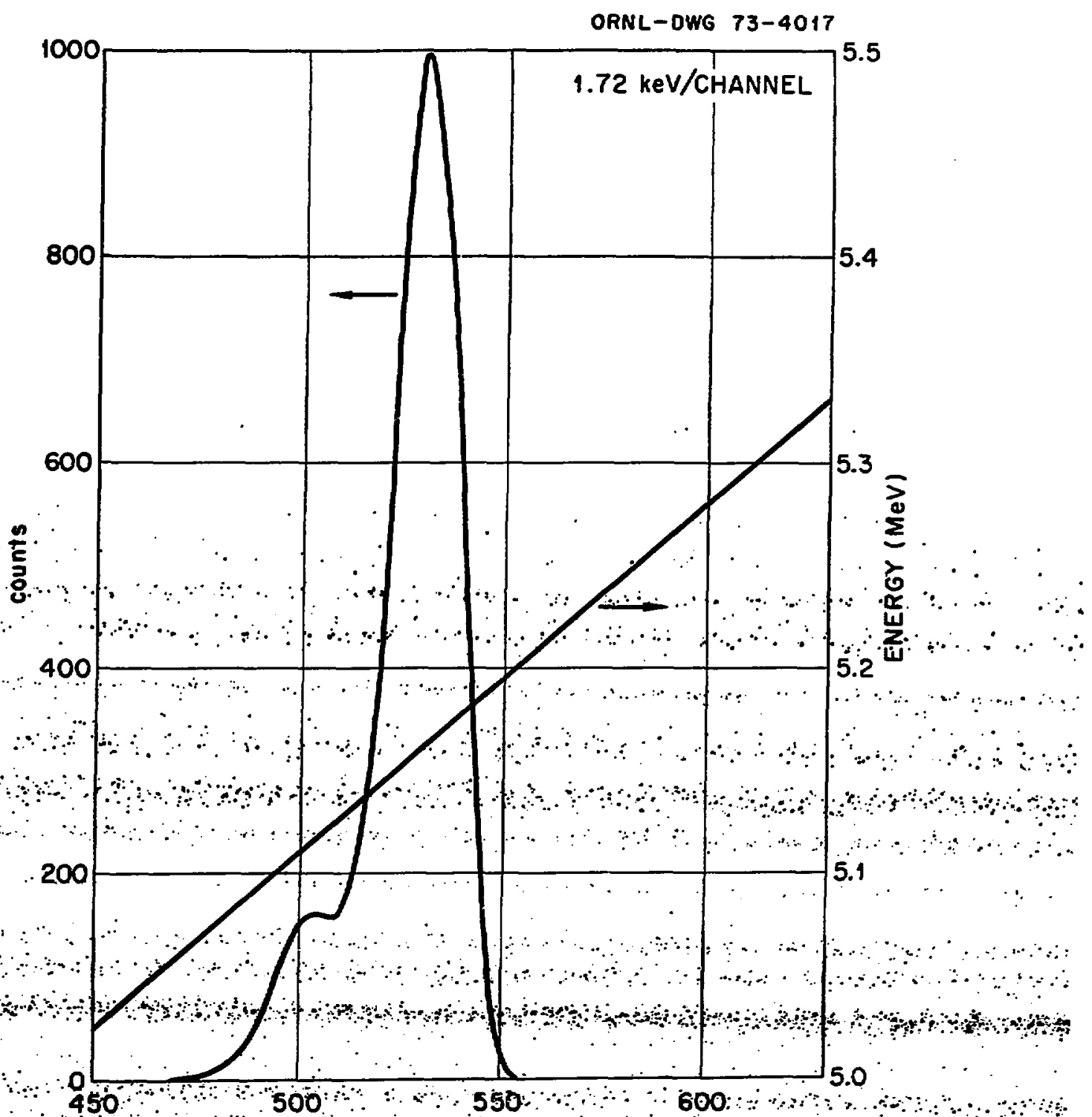

\section{CHANNEL NUMBER}

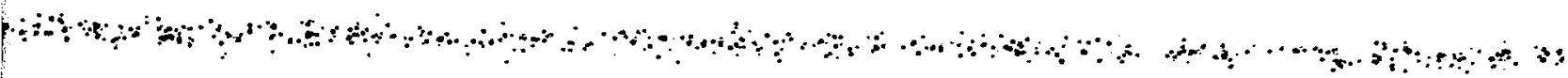


calibrate each counting system. The results are shown in Tables 12 and 13. The uniformity of the deposits was also checked by alpha counting several small areas of the folls. The folls were placed below a silicon detector which was collimated to detect only those alphas originating from a 3-mm diam spot. A schematic drawing of the system used to check the uniformity is shown in Fig. 9. The ${ }^{235} \mathrm{U}$ target was scanned in both the $x$ and $y$ directions and the results are shown in Fig. 10. The maximum deviation from the mean was $\pm 5 \%$. The uniformity of the ${ }^{239} \mathrm{Pu}$ deposit was determined around a circumference at various distances from the center of the target. The results are shown in Fig. 11. The numbers shown represent the number of counts (in thousands) obtained from a 3-mm dtam spot in 100 sec: Except for the outer edge, the $\cdots . .$. uniformity is well within a desired tolerance of $\neq 5 \%$. The outer edge variation is probably the result of a mask effect.

\section{Preparation of Homogeneous Alloys}

Homogeneous alloys of multigram quantities of various materials have been prepared using levitation and arc nelting. The se alloys have a औि normal concentration of $\sim 1 \%$ of the minor component and a normal concentrathon variation of < $0.5 \%$ Levitation melting is preferred over arc meiting

"because it is easier to obtain homogenization and subsequent rapid. quenchhing of the melt to produce the small grain size reguired for drawing wire $(0.08-\mathrm{mm}$ diam) whose concentration uniformity would be $\sim \pm 0.5 \%$ 
Table 12. ${ }^{235} \mathrm{U}$ Content of Fission Foils Determined by Gamma Counting

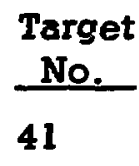

42

43

44

$44 A$

45

46

$46 \mathrm{~A}$

49

50 .

$5 i$

52

53

54.

$55^{\circ}$

\author{
$\mu \mathrm{g} / \mathrm{cm}^{2}$ \\ $(\gamma$ Counting $) \pm 0.5 \%$ \\ 99 \\ 91.2 \\ 92 \\ 130 \\ 105
}

140

116

95

26.8

$\therefore 25$

$\because 34$

32. 1

5.1. 0

33.6

36

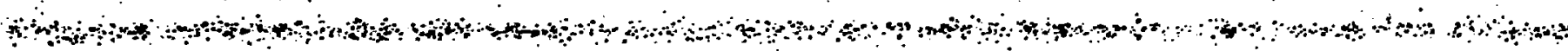

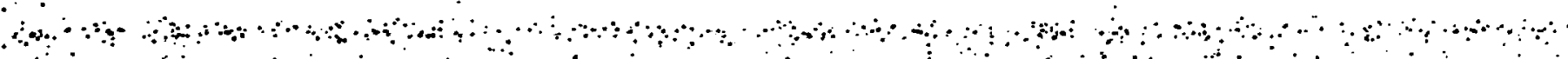

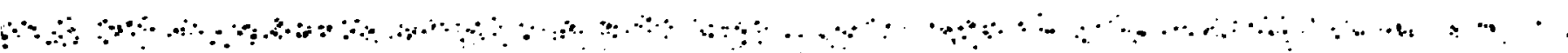




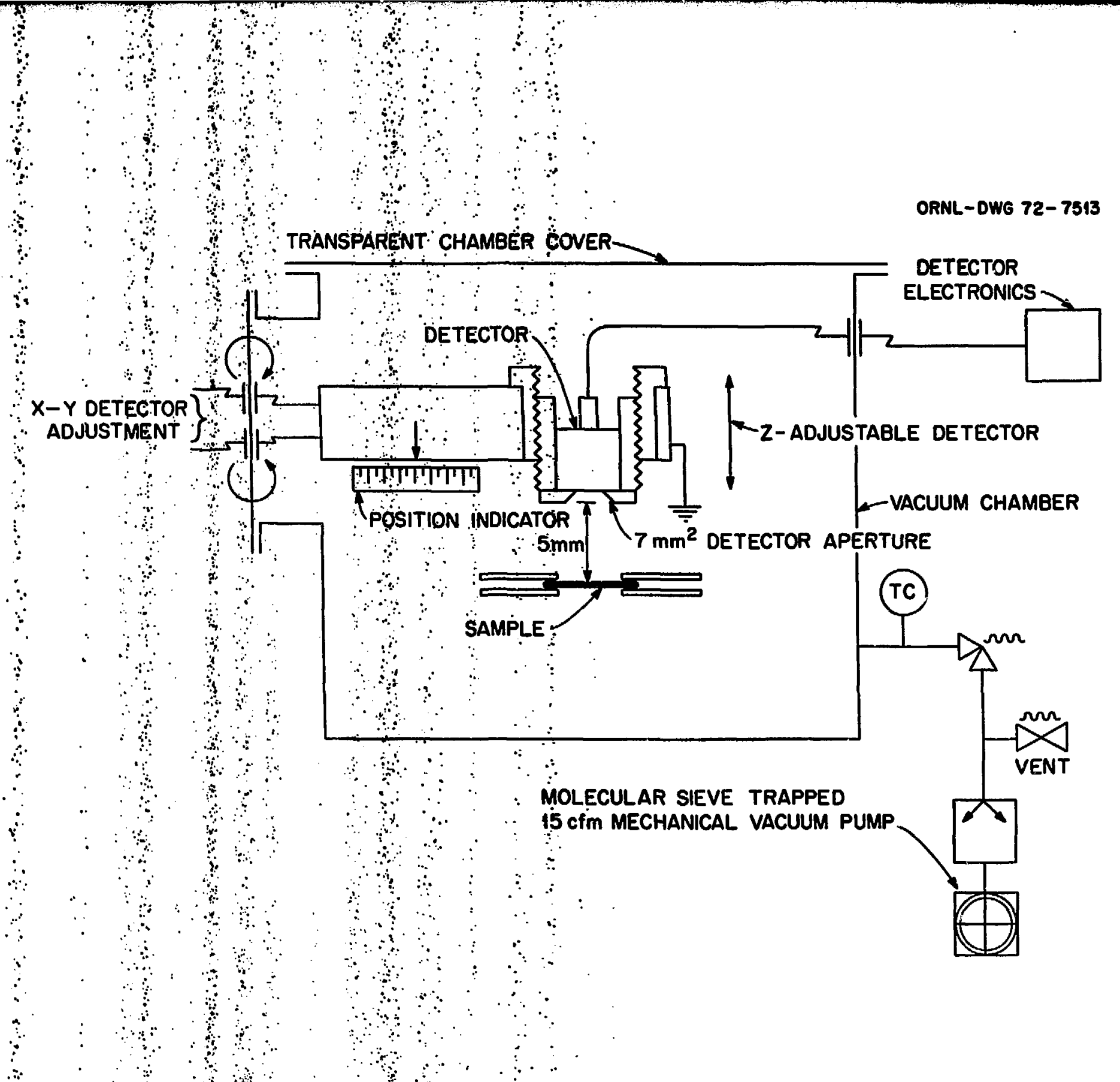




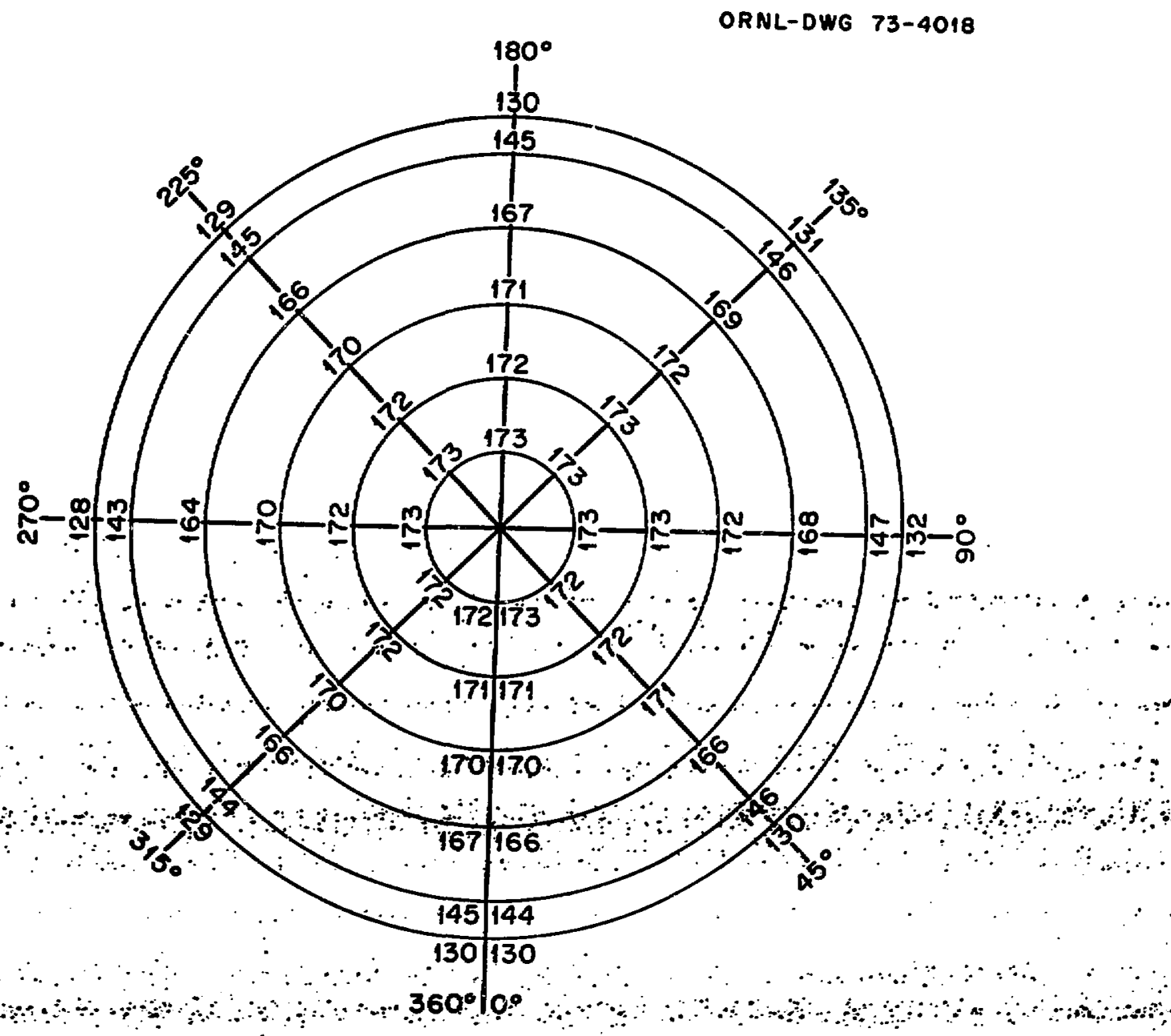

\section{Uniformity Mejosurement of ${ }^{239}$ pu Target Number 29}

$\therefore$ A 
per $\mathrm{cm}$ with regard to the minor component. Preliminary work has concentrated mainly on minor component alloys such as gold or cobalt with high purity vanadium for use in reactor dosimetry. Figure 12 shows a $10 \mathrm{~g}$ sample of vanadium containing 1.30 wt. $\%$ gold being levitated and melted using a $10 \mathrm{~kW}$ RF generator and a capacitor bank set at $0.06 \mu \mathrm{f}$ to match the RF unit with the load coil. The RF coll and procedures used are described in Ref. 5. Although this work is in its early stages, it appears that very homogeneous, well-defined alloys can be prepared for use in reactor dosimetry.

\section{$\underline{\text { Summary }}$}

The Issotopes Divișion of the Oak Ridge National Laboratory has estabrished a program for providing wëll-defined samples to be used for reactor dosimetry and precision neutron cross-section measurements.

The materials used, characterization of the materials and procedures are described: 


\section{References}

1. Neutron Dosimetry for Fast Reactor Applications, BNWL-SA-2887, p. 3, June 1970 .

2. Research Materials for Nuclear Measurements, CONF-711002, p. 86, Oct. 5-8, 1971, Gatlinburg, Tenn.

3. LMFBR Reaction Rate and Dosimetry 7th Quarterly Progress Report, Dec. 1972, Jan. -Feb. 1973, W/FFTF 732556, Hanford Engineering Development Laboratory, Operated by Westinghouse Hanford Co.

4. H. L. Adair, Preparation of Well-Defined Deposits of ${ }^{235} \mathrm{UO}_{2}$. To be published in Nucl. Inst. and Methods.

5. ANL-7398. 


\section{Figure List}

Fig. 1 ORNL Photo 101767 Dosimeter Capsules

Fig. 2 ORNL-Dwg. 73-10421 ${ }^{235}$ U Dosimeter Gamma Spectrum

Fig. 3 ORNL-Dwg. 73-10951 ${ }^{238} U$ Dosimeter Gamma Spectrum

Fig. 4 ORNL-Dwg. 73-10420 ${ }^{239}$ Pu Dosimeter Gamma Spectrum

Fig. 5 ORNL-Dwg. 73-10950 ${ }^{237} \mathrm{~Np}$ Dosimeter Gamma Spectrum

Fig. 6 ORNL-Dwg. $70-4190 \quad 270^{\circ} 10 \mathrm{~kW}$ Evaporation Source

Fig. 7 ORNL-Dwg. $73-3217 \quad{ }^{235} \mathrm{U}$ Alpha Spectrum for a $28 \mu \mathrm{g} / \mathrm{cm}^{2}$ Target

Fig. 8 ORNL-Dwg. 73-4017 ${ }^{239} \mathrm{Pu}$ Alpha Spectrum for a $60 \mu \mathrm{g} / \mathrm{cm}^{2}$ Target

Fig. 9 ORNL-Dwg. 72-7513 Schematic of System Used to Check Target Uniformity

Ffg. 10 ORNL-Dwg: $72-751 \mathrm{i}$ Uniformity of a ${ }^{235} \mathrm{U}$ Target Used In Fission Chamber

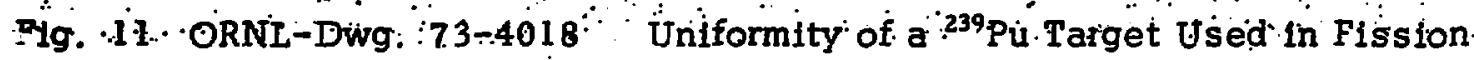
A

Fig. 12 ORNL Photo 2157-73 Levitation Melting of a 10-g Sample of V-Au 